\title{
Homogenization of instrumental time series of air temperature in Central Italy (1930-2015)
}

\author{
Eleonora Aruffo*, Piero Di Carlo
}

Department of Psychological, Health and Territorial Sciences, University ‘G. d'Annunzio' of Chieti-Pescara, 66100 Chieti, Italy

\begin{abstract}
Long-term and high quality instrumental air temperature data are important for reducing the uncertainty of past temperature trends at local and global scales, and for the projection of future expected changes. Currently this type of data is limited in the Mediterranean, which is particularly important since this region is considered a hot spot for climate change. To cover the data gap for Central Italy, a set of territorially dense long-term time series of temperature data covering different climate areas in the Abruzzo region is presented in this work. Due to the possible presence of inhomogeneities (non-climatology irregularities in the data set), a homogenization process was applied to the data. Monthly maximum and minimum temperatures measured at 22 stations were homogenized for the period 1930-2015 using the software HOMER v.2.6. All stations had at least 1 break in the time series, for a total of 89 and 80 inhomogeneities identified in the maximum and minimum temperature series, respectively. The annual amplitude of breaks in the annual series ranged between $0-4.44^{\circ} \mathrm{C}$ for the maximum temperatures and $0.01-3.75^{\circ} \mathrm{C}$ for the minimum temperatures. The trend of annual mean temperatures showed increasing temperatures at a regional level starting in the early $20^{\text {th }}$ century, with a greater rate especially after 1980 $\left(0.060^{\circ} \mathrm{C} \mathrm{yr}^{-1}\right)$. The temperature trends, analysed in 3 different intervals $(1930-1979,1950-2015$ and 1980-2015) for the 22 time series, demonstrate a slight increase in the rate of warming in the coastal and hilly area during the period 1930-1979 and highlight the importance of local measurements.
\end{abstract}

KEY WORDS: Homogenization $\cdot$ HOMER $\cdot$ Temperature $\cdot$ Italy $\cdot$ Observed climate data $\cdot$ Trends

\section{INTRODUCTION}

The availability and accessibility of high-quality surface temperature data are currently very limited worldwide, especially in the greater Mediterranean region (Brunet et al. 2014). This deficiency exists largely because (1) not all observed climate variables are routinely digitised and readily available, and (2) most of the data are not qualitatively and reasonably free of inhomogeneities (non-climatology irregularities), so they cannot be used in climate assessment (Gubler et al. 2017). Historical temperature data can be subjected to artificial and external perturbations that are not related to climate, such as relocation of the measurement stations, changes in instrumentation type and exposure, differences in land use and

${ }^{*}$ Corresponding author: eleonora.aruffo@unich.it land cover and historical events (WMO 2011). The consequence of these perturbations is the presence of inhomogeneities in the time series, which could result in sudden shifts of data values usually referred to as 'breaks' (in the case of instrument change or station relocation, for example), or a progressive bias (land use change). The station histories (metadata), if well documented, and the availability of simultaneous measurement data could allow identification of such inhomogeneities. However, often metadata availability is inadequate for homogenization purposes, and moreover, statistical homogenization is always recommended if the station density and spatial correlations allow such procedures to be followed (Aguilar et al. 2003, WMO 2011, Mamara et al. 2014).

(C) The authors 2019. Open Access under Creative Commons by Attribution Licence. Use, distribution and reproduction are unrestricted. Authors and original publication must be credited. 
Ribeiro et al. (2016) reviewed the available homogenization methods for climate data, presenting a classification and review of homogenization methods and homogenization software packages. The authors classified the statistical techniques, considering nonparametric (such as Pettitt 1979), classical (such as Craddock 1979), regression models (such as Allen at al. 1998) and Bayesian tests (Beaulieu et al. 2010). Ribeiro et al. (2016) also described techniques directly proposed as methods for climate data homogenization (i.e. homogenization procedures), such as (1) the Standard Normal Homogeneity Test (SNHT) (Alexandersson 1986, Alexandersson \& Moberg 1997), (2) Multiple Analysis of Series for Homogenization (MASH) (Szentimrey 1999), (3) PRODIGE (Caussinus \& Mestre 1996, 2004), (4) Climatol (Guijarro 2006, 2011), (5) Geostatistical Simulation Approach (Costa et al. 2008, Ribeiro et al. 2017), (6) USHCN (also known also as the Pairwise Homogenization Algorithm, PHA) (Menne \& Williams 2009), (7) RHTest (Wang 2008), (8) Adapted Caussinus-Mestre Algorithm for homogenizing Networks of Temperatures series (ACMANT) (Domonkos 2011), (9) ACMANT software package for the homogenization of temperature and precipitation (Domonkos 2014, Domonkos \& Coll 2017), and (10) HOMER (Mestre et al. 2013).

The HOMER software, used in our study, was developed in the framework of the European project COST Action ES0601, and includes some of the homogenization and quality control (QC) procedures of other homogenization software packages, such as (1) the data visualization and QC segments of Climatol (Guijarro 2011), (2) the pairwise detection of PRODIGE, hereafter 'pairwise detection' (Caussinus \& Mestre 2004), (3) the 'cghseg' joint detection method of Picard et al. (2011), hereafter 'joint detection', (4) the bivariate detection of ACMANT (Domonkos 2011), hereafter 'ACMANT detection' and (5) the ANOVA correction model of PRODIGE. During the COST project, the source methods of HOMER were tested together with several other homogenization methods, with results indicating that PRODIGE and ACMANT were among the best performing methods (Venema et al. 2012).

In Italy, Brunetti et al. (2006) homogenized 67 series of mean temperatures (1865-2003), 80\% of which were longer than $120 \mathrm{yr}$, and 48 maximum and minimum temperature series, $70 \%$ of which were longer than $120 \mathrm{yr}$, over the whole national territory, divided into 3 main climatic regions. Brunetti et al. (2006) used a revised version of the HOCLIS procedure (Auer et al. 1999), performing the homogenization in sub-groups of 10 series. In that analysis, only one station was homogenized in the Abruzzo region (L'Aquila, 1869-2003) and, in general, the main series were located in the northern (Po Valley, Alps and Tuscany regions) and southern (Apulia and Calabria regions) parts of Italy. Brunetti et al. (2006) found, after the homogenization procedure, a uniform increasing trend in the yearly mean temperature $\left(1 \mathrm{~K} \mathrm{century}^{-1}\right)$ in the Italian territory. They also performed a progressive trend analysis, showing that the trends in slope depend on the chosen interval. In fact, they found that considering the entire period (1865-2003), the minimum temperature rate of increase was greater than that of the maximum temperature; but, on the contrary, looking only at the last $50 \mathrm{yr}$, this result was reversed. From 2006, the Italian Institute for Environmental Protection and Research (ISPRA) started monitoring Italian climatological parameters, such as homogenized temperatures trends, through the Sistema nazionale per la raccolta, l'elaborazione e la diffusione di dati Climatici di Interesse Ambientale (SCIA) project. Analysing the SCIA's data set, ISPRA produces a report every year about the climate indicators in Italy (ISPRA 2017). However, the only station in the Abruzzo region employed by ISPRA for the yearly report is Pescara. Toreti \& Desiato (2008) homogenized 49 temperature series of the national air force weather service in Italy for the period 1961-2004, but none of the stations involved in that analysis was part of the Abruzzo territory. Finally, Scorzini et al. (2018) homogenized daily temperature data (1980-2012) over Abruzzo and Marche (a region neighbouring Abruzzo), to analyse extreme events in this area. In their study, the absolute maximum temperatures increased in 9 stations (Marche) at an average rate of $1.27^{\circ} \mathrm{C} \mathrm{decade}^{-1}$.

In this paper, we present the results of the homogenization procedure of maximum and minimum temperature series registered by the National Hydrographic Service (NHS; now Centro Funzionale of Abruzzo Region) at 22 different sites in the Abruzzo region. Long-term homogenized temperature series were produced using the HOMER homogenization software, in order to increase the spatial density of homogenized stations in the Mediterranean area, and to furnish a set of longer, homogenized, high-quality time series to be used for climate-related assessment.

\section{DATA AND METHODS}

The Abruzzo maximum and minimum temperature data set was provided by the NHS. Starting at the end of the $19^{\text {th }}$ century, stations were installed to 
Fig. 1. Location of the homogenized climate stations in central Italy, showing separation by regions of (A) coastal and hilly and

(B) mountainous areas
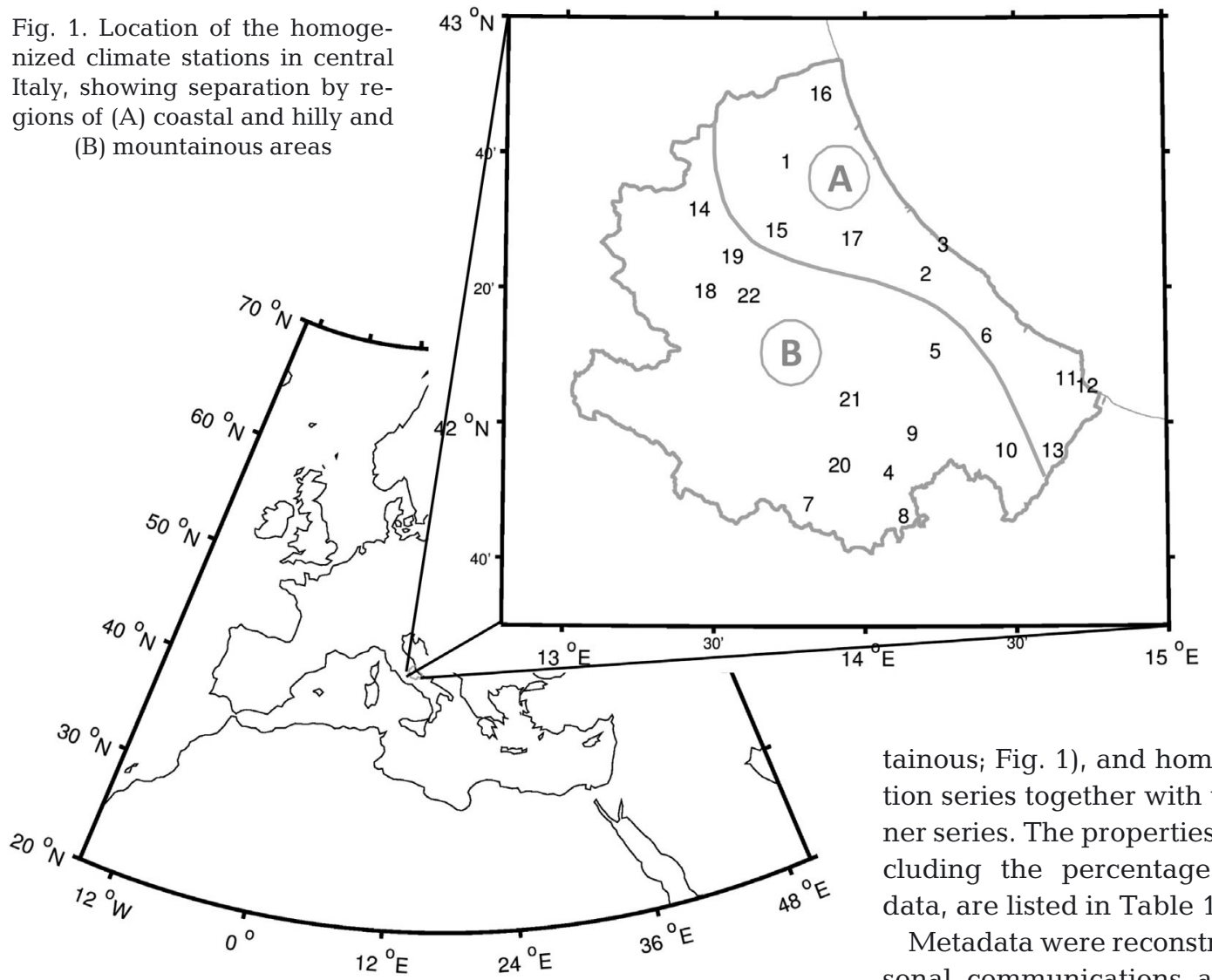

1. Teramo

2. Chieti

3. Pescara

4. Pescocostanzo

5. Guardiagrele

6. Lanciano

7. Pescasseroli

8. Castel di Sangro

9. Palena

10. Montazzoli

11. Scerni

12. Vasto

13. Palmoli

14. Campotosto

15. Isola del Gran Sasso

16. Nereto

17. Penne

18. L'Aquila

19. Assergi

20. Scanno

21. Sulmona

22. Barisciano

tainous; Fig. 1), and homogenized each station series together with their regional partner series. The properties of each station, including the percentage of available raw data, are listed in Table 1.

Metadata were reconstructed through personal communications and consultation of the NHS's archive. The annals that we had

monitor pluviometric data and, throughout the $20^{\text {th }}$ century, also included thermometric data over the whole national territory, divided into macro-regional areas. The Abruzzo region was mainly included in the Pescara macro-regional area, with the exception of the Fucino zone (a marshy area reclaimed at the end of the $19^{\text {th }}$ century), which was part of the Naple region. The NHS digitised the temperature data for 52 stations in the Pescara region starting in 1924. However, of the 52 total available stations, only 22 were selected for the homogenization procedure. The excluded stations were mainly those that had been installed recently or those with several years of missing data. We chose to homogenize the data from 1930-2015 for 15 stations, and from 1924-2015 for the remaining 7 stations corresponding mainly to the provinces of the Abruzzo region; specifically, we included Pescara in this dataset, in which data availability ranged from 1924 into the 2010s, as it is the most populated coastal town in Abruzzo. Our homogenization procedure included 2 steps: first, we selected the 7 stations with more temporally continuous data and homogenized them all together; then, we separated the 22 stations into 2 groups based on different geographic regions (coastal/hilly and mounthe opportunity to use covered the period from 1924-2003, while the station cards covered a shorter period (starting from approximately 1985 and finishing about 2000). Personal communications concerned relocation of some stations after 2000.

\subsection{The software: HOMER v.2.6}

To homogenize the temperature series collected in Abruzzo, we employed HOMER v.2.6, a free, R-based software for the homogenization of monthly or annual climate variables (Mestre et al. 2013). HOMER was developed to integrate, in a single software package, the advantages of some of the best methods currently in use. The structure of HOMER can be summarized as follows: (1) basic QC and network analysis adapted from Climatol (Guijarro 2011), (2) detection of break points with 3 different methods: the pairwise detection from PRODIGE (Caussinus \& Mestre 2004); the 'cghseg' joint detection (Picard et al. 2011); and the ACMANT detection (Domonkos 2011) and (3) a network-wide unified correction model (ANOVA, Caussinus \& Mestre 2004). It should be noted that 
a recent version of Climatol with improved properties has been developed (Guijarro 2018), which differs from the one used in HOMER; however, the changes did not involve the $\mathrm{QC}$ segment, which is included in HOMER. HOMER, finally, allows for the input of missing data and performs an unbiased reconstruction; consequently, the homogenized series the data set used in this paper does not show gaps in the monthly data.

Before homogenization, the monthly means of both of daily temperature maximums and minimums were calculated, as HOMER requires input data at a monthly resolution. With HOMER, the user employs automatic methods such as joint detection or ACMANT detection to confirm the results obtained by pairwise detection, which is a more subjective technique, allowing the use of the metadata. Pairwise detection is based on a comparison of the differences between a candidate series and its neighbours (identified by selecting one of two possible criteria: (1) the lower distance or (2) the higher correlation coefficient [R] between them). In contrast to ACMANT detection, this method does not need a composite reference series to be created, and a univariate detection process allows the detection of breaks. In any case, less evident breaks might remain hidden with pairwise detection, so the skill of the user is fundamental. Joint detection, based on a mixed linear model with the modified Bayes information criterion (Picard et al. 2011), is an automatic and quick procedure for break identification. Finally, ACMANT detection is very useful in the identification of breaks with a strong seasonal dependence, as it searches coincidental breaks in the series of annual means and the series of summerwinter differences. Note that ACMANT detection requires pre-homogenized reference series. Details and in-depth information about all the methods used in HOMER can be found elsewhere (Mestre et al. 2013). We chose to use the HOMER software to homogenize the monthly Abruzzo temperature data set considering that these long temporal series have never been homogenized, they present data gaps and show some evident inhomogeneities in many stations; thus, the flexibility and the semiautomatic methods in HOMER permitted us a more careful analysis of the homogenization process. The subjective approach of HOMER, in fact, allowed us to use the metadata (when available) to confirm some of the identified breaks, having the ability to check them by using automatic methods as well.

\subsection{QC and homogenization}

The homogenization procedure in HOMER is an iterative process, starting from a fast $\mathrm{QC}$ with outliers identified and removed, followed by the real homogenization procedure: after the first application of pairwise and joint detection analyses of the raw data, a first correction is performed, followed by an automatic pairwise detection control on the corrected series. Then, the ACMANT detection is run, which can confirm the detected breaks and help to identify others. After a new correction, pairwise and joint detection are applied again to the corrected series, and so on. The iterative process ends when no additional breaks are identified. In our analysis, we set the model parameters as follows: (1) to analyse temperature series, we selected the additive correction; (2) for the intercomparison of neighbours, we chose the criteria $\mathrm{R}>0.8$ and the inclusion of 6 stations, knowing that HOMER selected the first 6 stations even if they did not comply with the R threshold; and (3) we used the annual plus seasonal comparison option for pairwise detection.

\subsubsection{Preliminary QC}

A QC procedure was applied to the original daily data (when available) in accordance with WMO indications (WMO 2011, 2016). Specifically, we excluded the data outside extreme ranges $\left(>50\right.$ or $<-40^{\circ} \mathrm{C}$ ) in order to remove possible outliers due to errors in the registration of the data. Then we checked that the maximum temperature was always greater than the minimum temperature, deleting the daily data in which this condition was not met. In addition, we defined a monthly mean as valid only when no more than 5 daily values or 3 or more consecutive daily values were missing, following the restrictive WMO indications. Furthermore, we considered a year valid only when no more than 1 mo season ${ }^{-1}$ was missing (based on the solar year). Following these restrictions, we compiled the percentage of available data, listed in Table 1 for each station. Fig. 2 shows the availability of the raw data considering the restrictions described above: it is evident that for the period of the Second World War there is a lack of data availability in many stations, and that after about 2010 many stations were closed.

\subsubsection{Fast $\mathrm{QC}$ of HOMER}

HOMER, performing some Climatol tools, allows analysis of the main properties of the data series in 
Table 1. Name, National Hydrographic Service (NHS) code, latitude, longitude, altitude and percentage of available temperature $(T)$ data of each station. The stations homogenized in the first step are written in italics

\begin{tabular}{|c|c|c|c|c|c|}
\hline Stations & $\begin{array}{l}\text { NHS } \\
\text { code }\end{array}$ & $\begin{array}{c}\text { Latitude } \\
\left({ }^{\circ} \mathrm{N}\right)\end{array}$ & $\begin{array}{l}\text { Longitude } \\
\left({ }^{\circ} \mathrm{W}\right)\end{array}$ & $\begin{array}{l}\text { Altitude } \\
\text { (m a.s.l.) }\end{array}$ & $\begin{array}{c}\% \text { of } T \\
\text { data } \\
\text { available }\end{array}$ \\
\hline Teramo & 100 & $42^{\circ} 39^{\prime} 17^{\prime \prime}$ & $13^{\circ} 43^{\prime} 2^{\prime \prime}$ & 218 & 96.4 \\
\hline Chieti & 1060 & $42^{\circ} 22^{\prime} 37^{\prime \prime}$ & $14^{\circ} 10^{\prime} 59^{\prime \prime}$ & 278 & 96.7 \\
\hline Pescara & 1160 & $42^{\circ} 26^{\prime} 58^{\prime \prime}$ & $14^{\circ} 14^{\prime} 32^{\prime \prime}$ & 2 & 86.9 \\
\hline Pescocostanzo & 1180 & $41^{\circ} 53^{\prime} 17.5^{\prime \prime \prime}$ & $14^{\circ} 3^{\prime} 32.5^{\prime \prime}$ & 1461 & 89.4 \\
\hline Guardiagrele & 1240 & $42^{\circ} 11^{\prime} 13.6^{\prime \prime}$ & $14^{\circ} 12^{\prime} 52.3^{\prime \prime}$ & 551 & 77.7 \\
\hline Lanciano & 1330 & $42^{\circ} 13^{\prime} 32.9^{\prime \prime}$ & $14^{\circ} 23^{\prime} 4.1^{\prime \prime}$ & 298 & 81.4 \\
\hline Pescasseroli & 1350 & $41^{\circ} 48^{\prime} 34.3^{\prime \prime}$ & $13^{\circ} 47^{\prime} 32.3^{\prime \prime}$ & 1164 & 77.9 \\
\hline Castel di Sangro & 1420 & $41^{\circ} 46^{\prime} 51.9^{\prime \prime}$ & $14^{\circ} 6^{\prime} 29^{\prime \prime}$ & 800 & 74.4 \\
\hline Palena & 1570 & $41^{\circ} 59^{\prime} 2.2^{\prime \prime}$ & $14^{\circ} 8^{\prime} 15^{\prime \prime}$ & 781 & 72.1 \\
\hline Montazzoli & 1680 & $41^{\circ} 56^{\prime} 32.2^{\prime \prime}$ & $14^{\circ} 25^{\prime} 40.6^{\prime \prime}$ & 871 & 80.2 \\
\hline Scerni & 1700 & $42^{\circ} 7^{\prime} 6.9^{\prime \prime}$ & $14^{\circ} 37^{\prime} 48.3^{\prime \prime}$ & 125 & 79.1 \\
\hline Vasto & 1740 & $42^{\circ} 5^{\prime} 59.5^{\prime \prime}$ & $14^{\circ} 41^{\prime} 54.2^{\prime \prime}$ & 196 & 82.6 \\
\hline Palmoli & 1870 & $41^{\circ} 56^{\prime} 30.5^{\prime \prime}$ & $14^{\circ} 34^{\prime} 59.8^{\prime \prime}$ & 624 & 73.2 \\
\hline Campotosto & 190 & $42^{\circ} 32^{\prime} 10.1^{\prime \prime}$ & $13^{\circ} 24^{\prime} 23^{\prime \prime}$ & 1344 & 85.6 \\
\hline Isola del Gran Sasso & 260 & $42^{\circ} 29^{\prime} 4^{\prime \prime}$ & $13^{\circ} 39^{\prime} 53^{\prime \prime}$ & 545 & 83.5 \\
\hline Nereto & 30 & $42^{\circ} 49^{\prime} 18.6^{\prime \prime}$ & $13^{\circ} 48^{\prime} 46.1^{\prime \prime}$ & 165 & 91.7 \\
\hline Penne & 380 & $42^{\circ} 27^{\prime} 52^{\prime \prime}$ & $13^{\circ} 55^{\prime} 3^{\prime \prime}$ & 431 & 85.8 \\
\hline L'Aquila & 550 & $42^{\circ} 20^{\prime} 2^{\prime \prime}$ & $13^{\circ} 25^{\prime} 43^{\prime \prime}$ & 595 & 92.4 \\
\hline Assergi & 590 & $42^{\circ} 25^{\prime} 10.7^{\prime \prime}$ & $13^{\circ} 31^{\prime} 5.3^{\prime \prime}$ & 992 & 81.3 \\
\hline Scanno & 700 & $41^{\circ} 54^{\prime} 25^{\prime \prime}$ & $13^{\circ} 52^{\prime} 39^{\prime \prime}$ & 1045 & 88.4 \\
\hline Sulmona & 810 & $42^{\circ} 4^{\prime} 7^{\prime \prime}$ & $13^{\circ} 54^{\prime} 51^{\prime \prime}$ & 372 & 92.4 \\
\hline Barisciano & 920 & $42^{\circ} 19^{\prime} 25.3^{\prime \prime}$ & $13^{\circ} 34^{\prime} 26^{\prime \prime}$ & 978 & 90.5 \\
\hline
\end{tabular}

all stations, both before and after outlier removal. Specifically, Table 2 shows the R-values for the total data set after the first round of homogenization (i.e. for 7 homogenized and 15 non-homogenized station series, see Section 2): it is evident that R-values increase after removal of the outliers.

\subsubsection{Break detection}

After the outliers were removed, we ran pairwise detection followed by joint detection on the QC data to identify the more evident breaks, taking into account the available metadata. We defined an inhomogeneity if at least 3 stations in the neighbourhood identified it as such, taking into account both the annual and the seasonal breaks. After the correction, we ran the ACMANT detection to confirm the inhomogeneities found with a different technique. We did

the network: the number of data points available in the network for each year, the boxplot of the temperature values for each month and station, a histogram with the occurrence of temperature frequency intervals across the whole network, a correlogram of the first difference series as function of the distance between stations and, finally, an analysis of dissimilarity. These analyses allow further quality checks of the data relative to that described in Section 4.1. We did not identify any data quality problems at this step.

The HOMER software also includes the PRODIGE analysis of outliers. We visually identified the outliers for each station, inspecting the plots generated by HOMER in which the departure from each local anomaly is compared with the average anomaly computed over all stations in the neighbourhood; outliers are defined when the anomaly differs from the others for a specific month and station. In our analysis, we identified 395 outliers for maximum temperatures and 416 outliers for minimum temperatures, considering the whole data set of 22 stations (Fig. 3). The percentages of outliers found for each station with respect to the total available data set are shown in Table 2, which summarizes the correlation analysis between the reference series and those in the neighbourhood (automatically identified by HOMER) for not find any station series in the raw data set to be homogeneous, i.e. without inhomogeneities. In our procedure, breaks were first identified by pairwise detection; both joint detection and ACMANT detection were then used to confirm these breaks. In fact, joint detection results must be treated with caution due to the problems reported by Gubler et al. (2017) and Domonkos (2017).

Considering that the primary objective of ACMANT detection is to find inhomogeneities with seasonally varied biases, we used it to better identify those breaks with seasonal dependence. In this case as well, we validated the seasonal breaks only if they were confirmed by pairwise detection (breaks present in at least 3 stations of the neighbourhood). We found a total of 89 and 80 inhomogeneities in the maximum and minimum temperature series, respectively (Fig. 4). All inhomogeneities found for each station are reported in Tables S1 \& S2 in the Supplement at www.int-res.com/articles/suppl/c077 p193_supp.pdf, which also states if they were confirmed by the metadata and by ACMANT detection. The majority of the 7 stations homogenized during the first step did not show any other inhomogeneities when they were included in the second step of the homogenization, with the exception of 


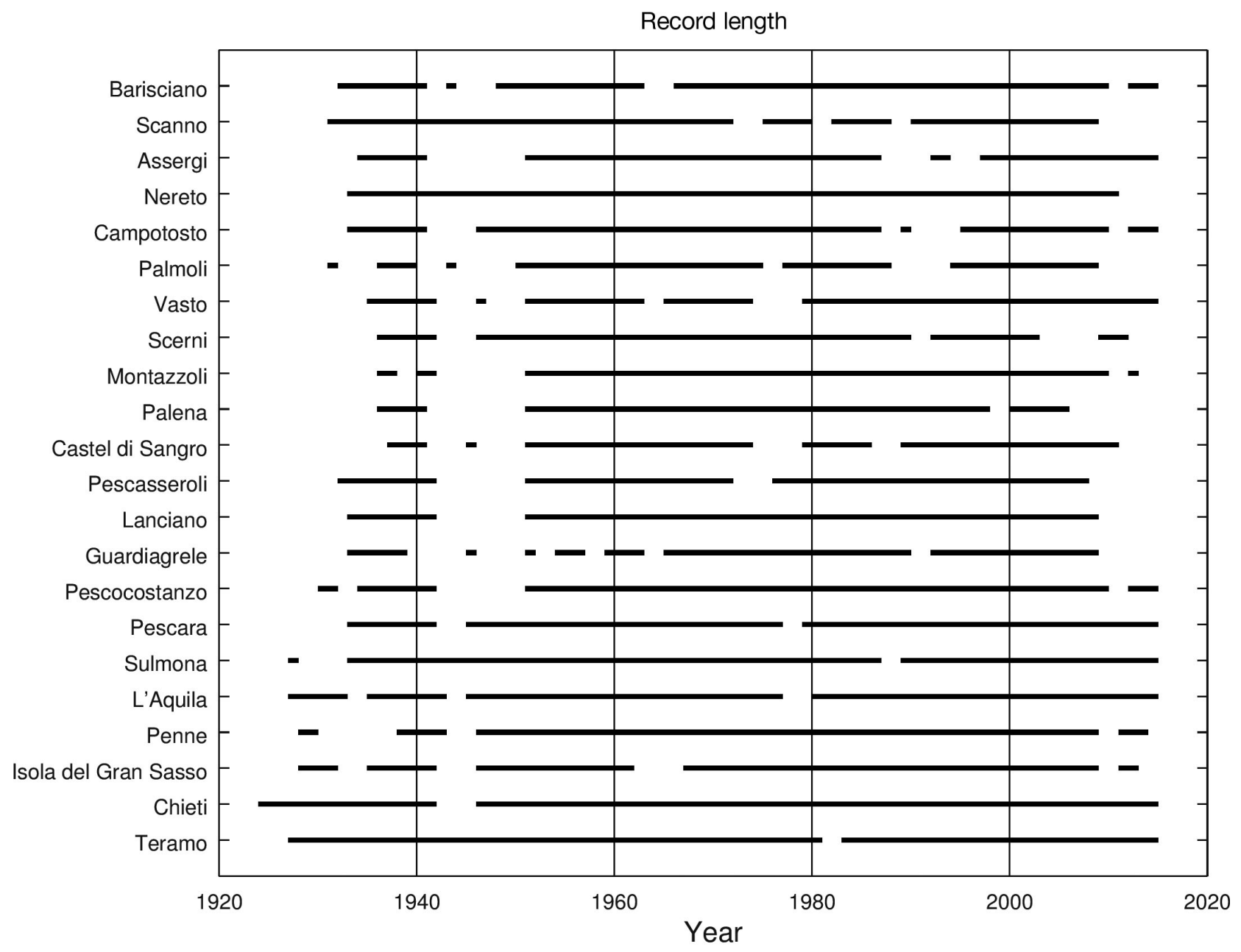

Fig. 2. Record length before the homogenization procedure of the complete data set

Teramo station (maximum temperatures); this is highlighted in grey in Table S1. We chose to select the break points that were identified by pairwise detection in HOMER and, when possible, confirmed them using the metadata. We did not confirm breaks suggested only by the metadata and not also supported by the statistical analysis in HOMER. We considered a break to be confirmed by metadata when the maximum difference between the breaks and the metadata was less than $2 \mathrm{yr}$. We fixed the same interval for the ACMANT detection. Tables S1 \& S2 indicate the following nature of the interventions, as reconstructed by the metadata: (1) a change in the altitude above sea level (a.s.l.) of the stations or in the instrument height above the ground; (2) a change in the type of instruments in use; (3) relocation; (4) a new operator for the station and (5) annotations about instrument maintenance. Unfortunately, the longest data set of available metadata (i.e. the annals) reports only changes in altitude and instrumentation type, without reporting instrument maintenance such as calibration, interventions in the stations, operators, etc. The main causes of the inhomogeneities documented by the metadata were changes in measurement techniques or station/instrument relocations. Overall, we found that (1) 47.2 and $41.3 \%$ of the inhomogeneities were confirmed by the metadata for the maximum and minimum temperatures, respectively and (2) 80.9 and $77.5 \%$ of the inhomogeneities were confirmed by the ACMANT detection analysis for the maximum and minimum temperatures, respectively. The percentage of breaks confirmed by the metadata is in line with those found in other homogenization analyses: Mamara et al. (2014) found that $32 \%$ of the total inhomogeneities were confirmed by metadata information and that the majority of the metadata corresponded to breaks; Osadchyi et al. (2018) confirmed $31 \%$ of breaks by using historical information. 

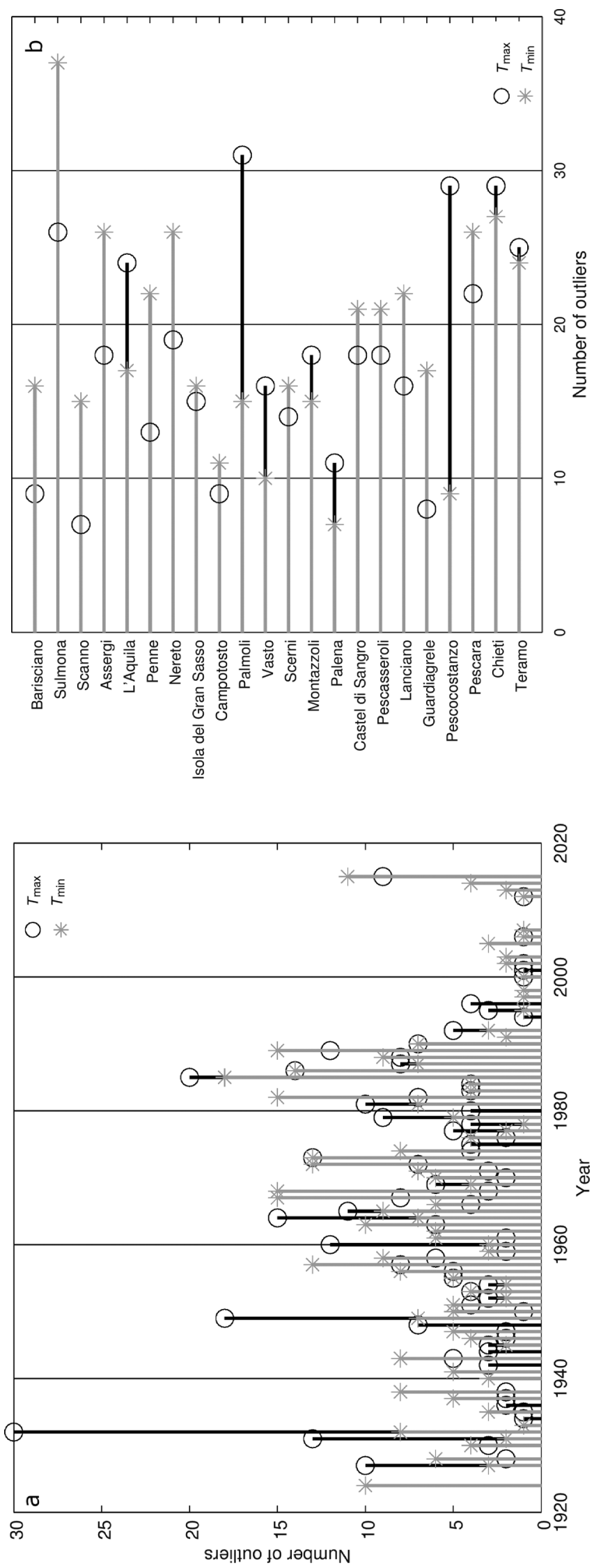

After the breaks were identified, we ran the 'assess month' function of HOMER in order to assess the positions of the identified breaks at a monthly resolution, although it must be noted that true break positions might differ from the detected break positions even when the best detection methods are used, and the detection accuracy has a statistical connection with the break magnitude (Lindau \& Venema 2016). Finally, we checked the inhomogeneities with ACMANT detection again; the percentage of confirmed ACMANT break detections is relative to this final check. The break highlighted by an asterisk in Table S1 was not considered as confirmed by the metadata, because the metadata were not clearly definable.

\subsubsection{Iteration and correction}

The correction procedure in HOMER is an iterative process, starting with pairwise and joint detections applied to the $\mathrm{QC}$ data, and then correcting them for the first time. Subsequently, we ran the same procedure again (when necessary), as suggested by Mestre et al. (2013). The corrections were performed with the ANOVA correction model. After a correction step, the ACMANT detection was applied to the prehomogenized series in order to confirm the breaks highlighted by pairwise detection. The HOMER procedure cyclically proceeds between correction, pairwise and joint detection on corrected series, and ACMANT detection until no more breaks are detected. In our analysis, we usually ran this recursive cycle between 2 and 5 times before considering the homogenization procedure complete.

We found that all analysed series had at least one break. The annual amplitude of the breaks, expressed in absolute values, that were evaluated for the annual series are shown in Fig. 5 in terms of relative frequency distributions. The annual amplitude of the breaks in maximum temperatures ranged between 0 and $4.44^{\circ} \mathrm{C}$; about $75 \%$ of the breaks had an amplitude at annual scale lower than $2.27^{\circ} \mathrm{C}$ (Fig. 5). For minimum temperatures, the break annual amplitude ranged between 0.01 and $3.75^{\circ} \mathrm{C}$ and about $70 \%$ of the breaks in the annual series had an annual amplitude lower than $1.35^{\circ} \mathrm{C}$ (Fig. 5). 
Table 2. Correlation coefficient analysis for the complete temperature data set. The 7 stations homogenized in the first step are written in italics. Correlations (R-values) were evaluated between each reference station (listed in the first column) and the first 6 best correlated stations of the neighbourhood

\begin{tabular}{|c|c|c|c|c|c|c|c|c|c|c|}
\hline \multirow{3}{*}{$\begin{array}{l}\text { Reference } \\
\text { stations }\end{array}$} & \multicolumn{4}{|c|}{$\longrightarrow$ Pre-outlier removal $\longrightarrow$} & \multicolumn{6}{|c|}{ - Post-outlier removal } \\
\hline & \multicolumn{2}{|c|}{ Maximum temperature } & \multicolumn{2}{|c|}{ Minimum temperature } & \multicolumn{3}{|c|}{ Maximum temperature } & \multicolumn{3}{|c|}{ Minimum temperature } \\
\hline & $R_{\min }-R_{\max }$ & $\bar{R}$ & $R_{\min }-R_{\max }$ & $\bar{R}$ & $R_{\min }-R_{\max }$ & $\bar{R}$ & $\%$ outliers & $R_{\min }-R_{\max }$ & $\bar{R}$ & $\%$ outliers \\
\hline Teramo & $0.70-0.83$ & 0.77 & $0.53-0.69$ & 0.61 & $0.76-0.85$ & 0.80 & 1.72 & $0.61-0.74$ & 0.66 & 0.82 \\
\hline Chieti & $0.70-0.85$ & 0.76 & $0.56-0.72$ & 0.65 & $0.70-0.87$ & 0.79 & 1.00 & $0.56-0.81$ & 0.67 & 1.09 \\
\hline Pescara & $0.64-0.82$ & 0.75 & $0.45-0.64$ & 0.56 & $0.72-0.85$ & 0.78 & 0.63 & $0.51-0.74$ & 0.62 & 1.27 \\
\hline Pescocostanzo & $0.54-0.64$ & 0.60 & $0.46-0.69$ & 0.54 & $0.62-0.71$ & 0.66 & 3.14 & $0.53-0.70$ & 0.61 & 0.98 \\
\hline Guardiagrele & $0.42-0.60$ & 0.48 & $0.43-0.60$ & 0.49 & $0.49-0.72$ & 0.57 & 1.00 & $0.45-0.65$ & 0.55 & 2.12 \\
\hline Lanciano & $0.55-0.67$ & 0.62 & $0.47-0.58$ & 0.52 & $0.65-0.88$ & 0.73 & 1.90 & $0.51-0.77$ & 0.62 & 2.62 \\
\hline Pescasseroli & $0.52-0.69$ & 0.61 & $0.53-0.68$ & 0.59 & $0.61-0.76$ & 0.70 & 2.24 & $0.55-0.73$ & 0.65 & 2.61 \\
\hline Castel di Sangro & $0.49-0.65$ & 0.56 & $0.52-0.62$ & 0.57 & $0.60-0.76$ & 0.77 & 2.34 & $0.44-0.67$ & 0.53 & 2.73 \\
\hline Palena & $0.60-0.75$ & 0.66 & $0.54-0.68$ & 0.61 & $0.71-0.82$ & 0.77 & 1.48 & $0.62-0.73$ & 0.68 & 0.94 \\
\hline Montazzoli & $0.59-0.74$ & 0.64 & $0.51-0.72$ & 0.60 & $0.69-0.82$ & 0.74 & 2.17 & $0.61-0.72$ & 0.69 & 1.81 \\
\hline Scerni & $0.49-0.62$ & 0.52 & $0.30-0.52$ & 0.39 & $0.61-0.75$ & 0.68 & 1.72 & $0.47-0.59$ & 0.53 & 1.96 \\
\hline Vasto & $0.55-0.66$ & 0.60 & $0.44-0.63$ & 0.55 & $0.62-0.76$ & 0.70 & 1.88 & $0.59-0.73$ & 0.65 & 1.17 \\
\hline Palmoli & $0.67-0.73$ & 0.71 & $0.52-0.71$ & 0.58 & $0.76-0.88$ & 0.80 & 4.11 & $0.59-0.77$ & 0.69 & 1.99 \\
\hline Campotosto & $0.64-0.70$ & 0.67 & $0.57-0.74$ & 0.66 & $0.71-0.77$ & 0.73 & 1.02 & $0.56-0.72$ & 0.65 & 1.25 \\
\hline Isola del Gran Sasso & $o \quad 0.69-0.82$ & 0.76 & $0.56-0.72$ & 0.65 & $0.78-0.90$ & 0.83 & 0.76 & $0.60-0.85$ & 0.71 & 0.45 \\
\hline Nereto & $0.69-0.78$ & 0.72 & $0.51-0.58$ & 0.55 & $0.73-0.82$ & 0.78 & 2.01 & $0.56-0.76$ & 0.62 & 2.75 \\
\hline Penne & $0.73-0.85$ & 0.80 & $0.58-0.72$ & 0.66 & $0.82-0.90$ & 0.85 & 0.27 & $0.67-0.85$ & 0.74 & 1.00 \\
\hline L'Aquila & $0.68-0.81$ & 0.75 & $0.50-0.61$ & 0.56 & $0.76-0.82$ & 0.79 & 0.72 & $0.52-0.61$ & 0.57 & 0.27 \\
\hline Assergi & $0.48-0.61$ & 0.54 & $0.40-0.54$ & 0.45 & $0.53-0.66$ & 0.60 & 2.15 & $0.50-60$ & 0.55 & 3.10 \\
\hline Scanno & $0.52-0.72$ & 0.65 & $0.36-0.46$ & 0.40 & $0.66-0.80$ & 0.74 & 0.77 & $0.43-0.72$ & 0.51 & 1.64 \\
\hline Sulmona & $0.61-0.78$ & 0.69 & $0.53-0.67$ & 0.61 & $0.72-0.82$ & 0.77 & 0.72 & $0.59-0.69$ & 0.63 & 0.54 \\
\hline Barisciano & $0.65-0.81$ & 0.72 & $0.53-0.74$ & 0.61 & $0.73-0.80$ & 0.76 & 0.96 & $0.53-0.67$ & 0.61 & 1.71 \\
\hline
\end{tabular}

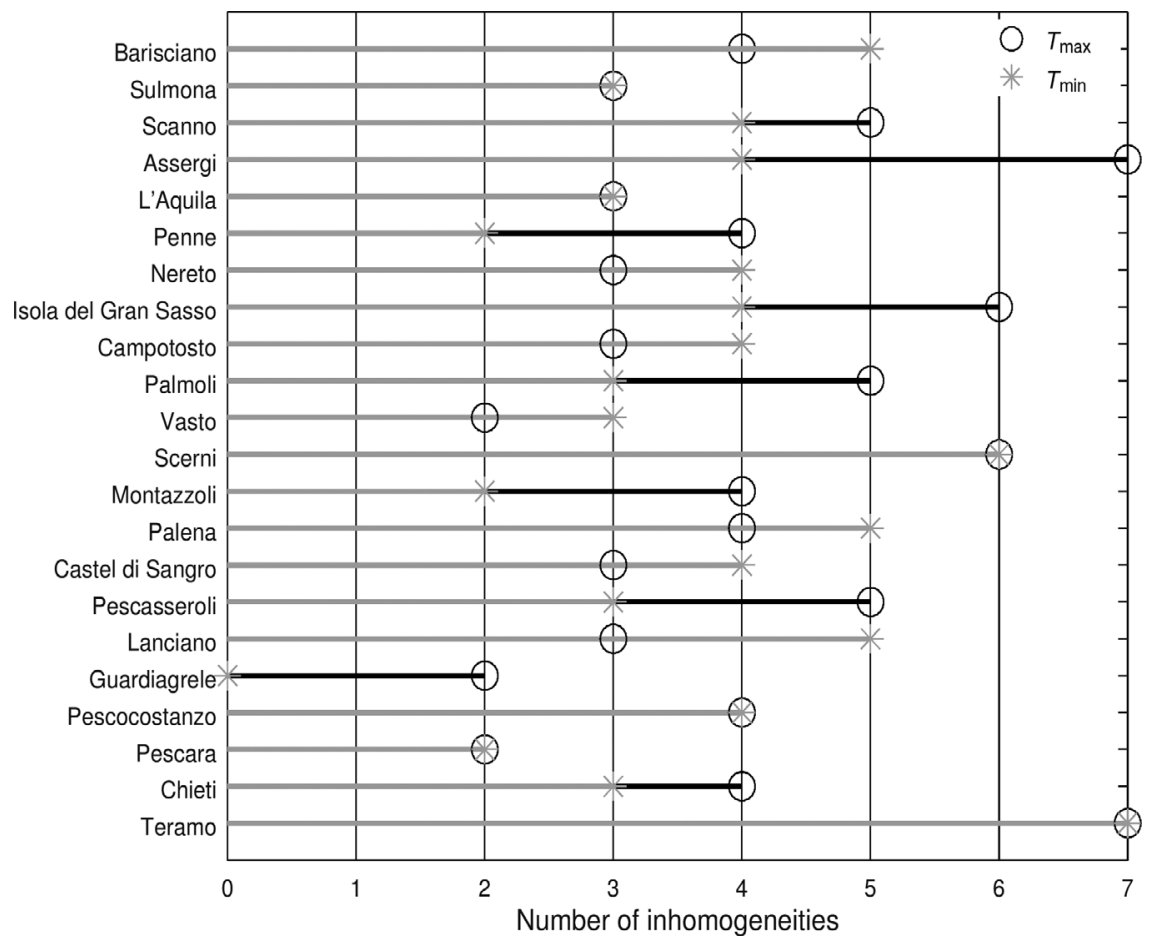

Fig. 4. Inhomogeneities found for each station for both the maximum $\left(T_{\max }\right)$ and minimum $\left(T_{\min }\right)$ temperatures

\section{RESULTS AND DISCUSSION}

Fig. 6 shows the time series of the homogenized regional annual mean temperatures obtained by averaging the 22 maximum and minimum temperature series of the stations analysed. We calculated the linear trends (least-squares best fit) for different temporal intervals, highlighting that the temperature showed an abrupt increase after 1980. Between 1924 and 1979, the annual mean temperature in the Abruzzo region increased with a slope of $0.03^{\circ} \mathrm{C}$ decade $^{-1}$, between 1950 and 2015 it increased at a rate of $0.42^{\circ} \mathrm{C}$ decade $^{-1}$ and, finally, between 1980 and 2015 the slope of the linear regression reached $0.60^{\circ} \mathrm{C}$ decade $^{-1}$. These results suggest that the annual mean temperature in the Abruzzo region is increasing at varying rates in the last century with a higher rate after 1980. This is in line with what has also been found for the global 

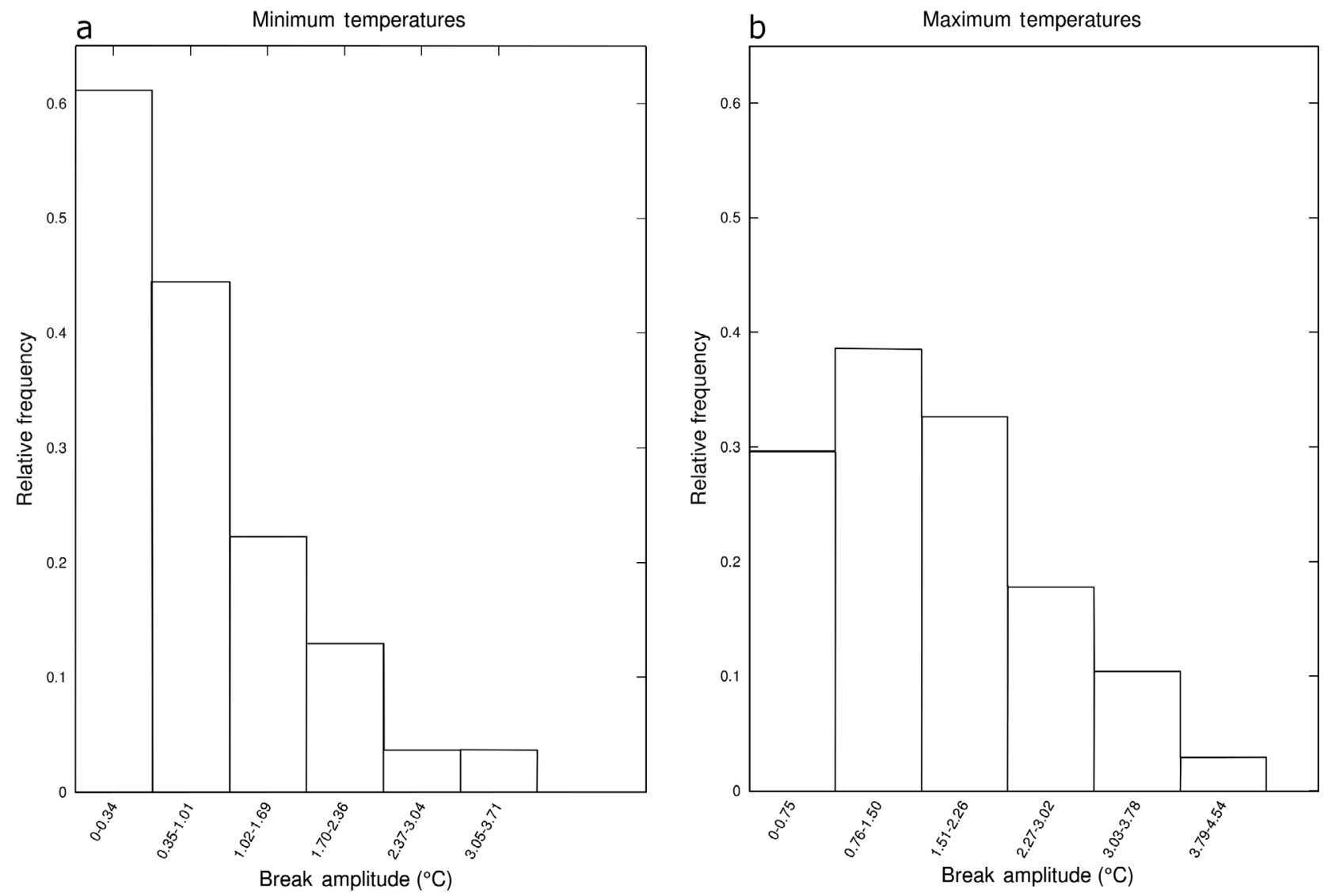

Fig. 5. Annual amplitude of the breaks, in absolute values, for the (a) minimum and (b) maximum temperatures, expressed as relative frequency distributions

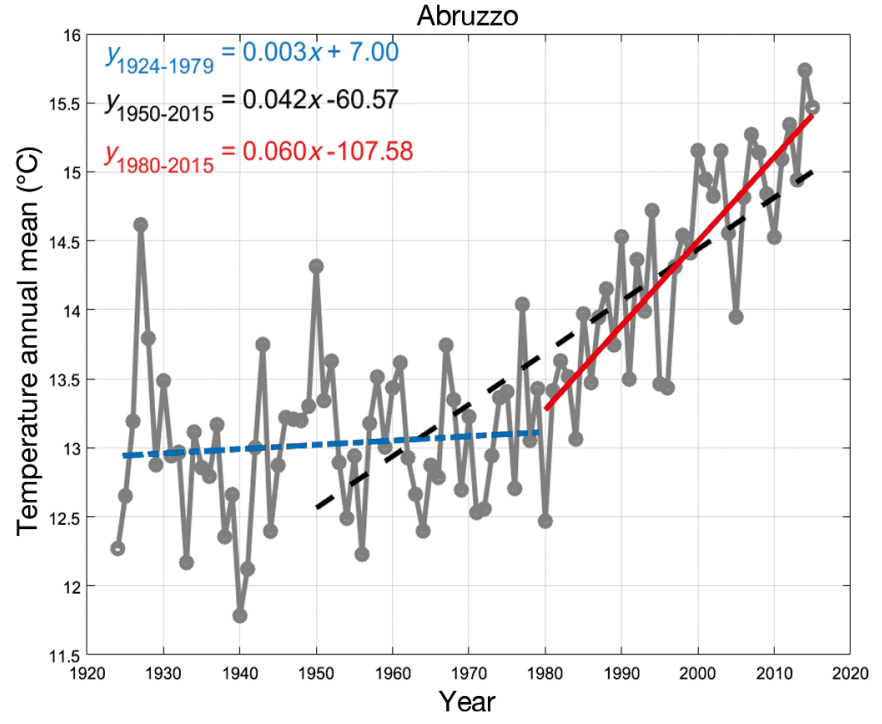

Fig. 6. Annual mean temperatures for the Abruzzo region (obtained by averaging the maximum and minimum temperature series of all stations). A linear regression model (least-squares best fit) was applied in different temporal intervals in order to find the slopes as function of period in the analysis mean temperature (Trenberth et al. 2007, Hartmann et al. 2013). We compared our results with temperature trends that have been found for similar regions in the Mediterranean area. Antolini et al. (2016) analysed the mean temperature trend over the EmiliaRomagna region $(300 \mathrm{~km}$ north of the sites analysed in this study), reporting increases at some stations of up to $0.5^{\circ} \mathrm{C}_{\text {decade }}^{-1}$ (1961-2010). Furthermore, Marletto et al. (2009) produced a hydro-climatic atlas for the Emilia-Romagna region, evaluating increasing trends during the period 1961-2008 of 0.25 and $0.46^{\circ} \mathrm{C}$ decade $^{-1}$ for minimum and maximum mean temperatures, respectively. The Annual Bulletin on the Climate in WMO Region VI (DWD 2011) showed the trend analysis map for annual temperatures (1951-2011) and revealed that, in the region of interest (central-southern Italy), the trends were greater than $0.3^{\circ} \mathrm{C}$ decade ${ }^{-1}$. Finally, Liuzzo et al. (2017) investigated the long-term temperature changes in Sicily during the 1924-2013 period and indicated that at some sites, the maximum temperature had a positive trend of $0.5^{\circ} \mathrm{C}$ decade ${ }^{-1}$. Fig. 7 depicts the 
spatial distribution of the temperature trends in the Abruzzo region, showing the slopes of linear regression for the annual mean temperatures (Fig. 7a), the maximum temperatures (Fig. $7 \mathrm{~b}$ ) and the minimum temperatures (Fig. $7 \mathrm{c}$ ), evaluated over 3 different time periods: $1930-1979,1950-2015$ and 1980-2015. The local variability of the rate of temperature change is quite pronounced and differs among the different time intervals as well as for the maximum, minimum and annual mean temperatures. One example of this difference is that in the first period considered (1930-1979), the rate of temperature change was slightly higher in the coast-hill parts of the region compared to mountain areas, whereas in the periods 1950-2015 and 1980-2015, the variations were more scattered with less evidence of definite areas having higher changes than others. These results confirm the importance of using homogenized data series of maximum and minimum temperatures to better describe the local impact of climate change and regional temperature trends. It is evident that some sites (such as Pescara and Teramo in Fig. 7, with increases of $0.9^{\circ} \mathrm{C}$ decade $^{-1}$ ) in the $1980-2015$ period present greater increasing temperature trends
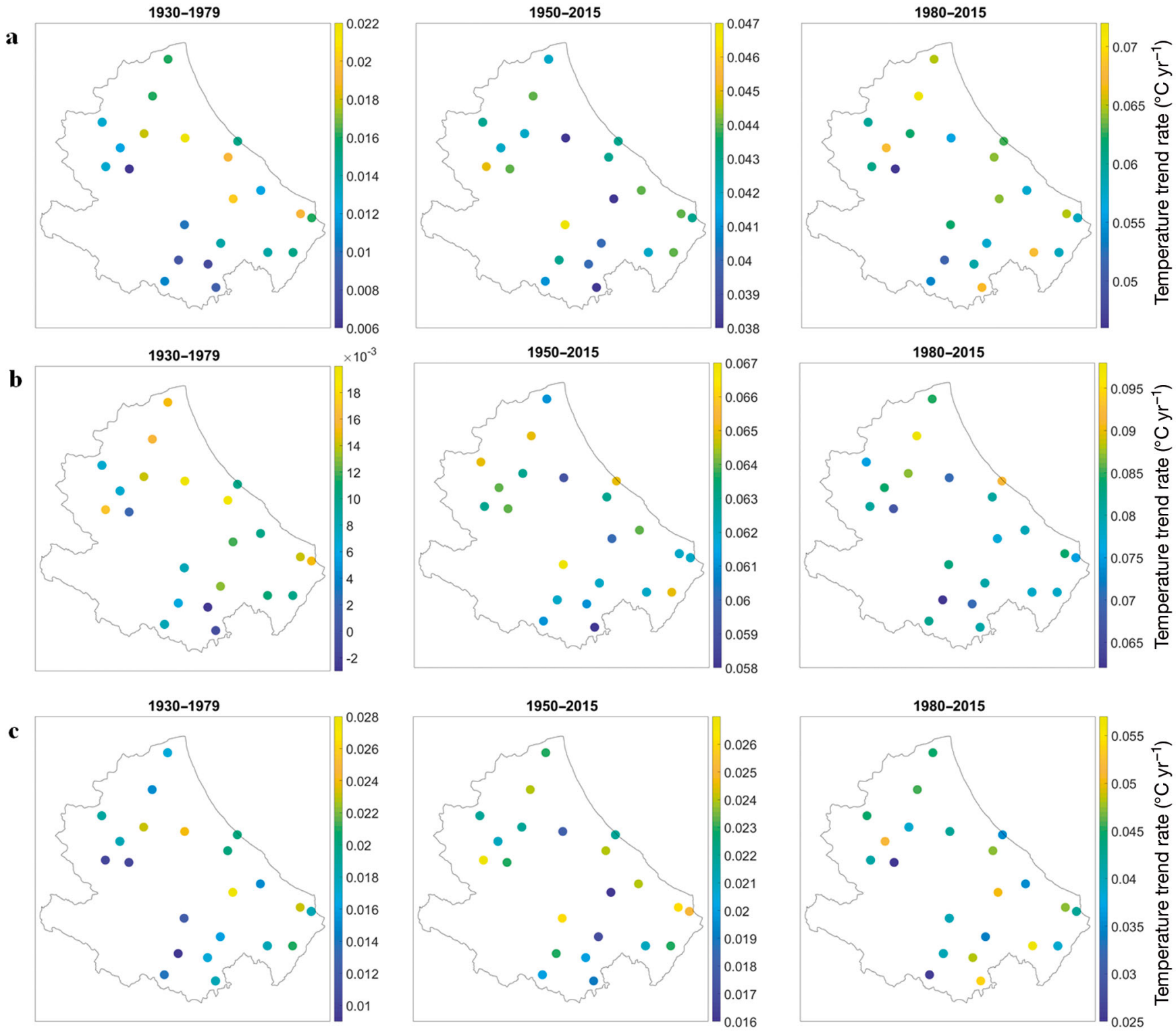

Fig. 7. Spatial temperature trend rates of the Abruzzo region: (a) annual mean temperature, (b) maximum temperature and (c) minimum temperature. The slopes of linear regression models, applied to the homogenized data set of 22 series, have been evaluated in 3 different temporal intervals (from left to right): 1930-1979; 1950-2015 and 1980-2015 
than that at the regional level $\left(0.78^{\circ} \mathrm{C}\right.$ decade $\left.^{-1}\right)$. Moreover, the difference between local and regional trends is more variable in the 1980-2015 period compared to the 1950-2015 period. It is also evident that in some sites (such as Castel di Sangro in Fig. 7, with an increase of about $0.7^{\circ} \mathrm{C}$ decade ${ }^{-1}$ ) the major impact is on the minimum temperatures, since the annual mean temperature trends (1980-2015) were greater than the regional annual mean trend $\left(0.6^{\circ} \mathrm{C}\right.$ decade $^{-1}$ ).

\section{CONCLUSIONS}

We homogenized the series of maximum and minimum temperatures recorded at 22 different sites (mountains, valleys, hills and sea coast) in the Abruzzo region (central Italy). With the application of the software HOMER, we identified 395 and 416 outliers in the maximum and minimum temperatures, respectively. The pairwise, joint and ACMANT detection analyses allowed us to detect a total of 89 and 80 breaks in the maximum and minimum temperature series, respectively. About 47.2 and $41.3 \%$ of the inhomogeneities were confirmed by the metadata for the maximum and minimum temperatures, respectively. About 80.9 and $77.5 \%$ of the inhomogeneities were confirmed by the ACMANT detection analysis for the maximum and minimum temperatures, respectively. The lack of metadata did not allow us to verify more breaks, but the correspondence between the pairwise and ACMANT detection results confirmed that the detected breaks were relevant. The homogenized data set covers a gap of temperature data over the period 1930-2015 in central Italy, extending from the coast of the Adriatic Sea to high mountain areas; hence, this information will enrich the Greater Mediterranean area temperature series with a long-term and high-quality surface data set that can be used for climate-related assessments and for climate products and services. Spatial heterogeneities of minimum, maximum and annual mean temperature changes across the different temporal intervals analysed are highlighted, showing the presence of different trends between the coastal and mountain regions during the period 1930-1979.

Acknowledgements. We thank Mario Cerasoli and Antonio Iovino of the Centro Funzionale of Abruzzo Region, for access to their temperatures database and for supporting us in the metadata reconstruction. Moreover, we thank Dr. Mestre and Dr. Dubuisson (Meteo France) for their help in the use of the HOMER software. This work was partially supported by Fondi di Ricerca Dipartimentali (DiSPuTer - 2017).

\section{LITERATURE CITED}

Aguilar E, Auer I, Brunet M, Peterson TC, Wieringa J (2003) Guidelines on climate metadata and homogenization. World Meteorological Organization Technical Document No. 1186. WMO, Geneva

* Alexandersson H (1986) A homogeneity test applied to precipitation data. Int J Climatol 6:661-675

Alexandersson H, Moberg A (1997) Homogenization of Swedish temperature data. I. Homogeneity test for linear trends. Int J Climatol 17:25-34

Allen R, Pereira L, Raes D, Smith M (1998) Statistical analysis of weather data sets, crop evapotranspirationguidelines for computing crop water requirements. Irrigation and Drainage Paper No. 56. FAO, Rome

Antolini G, Auteri L, Pavan V, Tomei F, Tomozeiu R, Marletto V (2016) A daily high-resolution gridded climatic data set for Emilia-Romagna, Italy, during 1961-2010. Int J Climatol 36:1970-1986

Auer I, Böhm R, Schöner W, Hagen M (1999) ALOCLIMAustrian-central European long-term climate-creation of a multiple homogenized long-term climate data-set. In: Proc $2^{\text {nd }}$ seminar for homogenisation of surface climatological data, 9-13 November 1998, Budapest. WMO, Budapest, p 47-71

* Beaulieu C, Ouarda TBMJ, Seidou O (2010) A Bayesian normal homogeneity test for the detection of artificial discontinuities in climatic series. Int J Climatol 30:2342-2357

Brunet M, Jones PD, Jourdain S, Efthymiadis D, Kerrouche M, Boroneant C (2014) Data sources for rescuing the rich heritage of Mediterranean historical surface climate data. Geosci Data J 1:61-73

Brunetti M, Maugeri M, Monti F, Nanni T (2006) Temperature and precipitation variability in Italy in the last two centuries from homogenised instrumental time series. Int J Climatol 26:345-381

Caussinus H, Mestre O (1996) New mathematical tools and methodologies for relative homogeneity testing. In: Proc $1^{\text {st }}$ seminar for homogenization of surface climatological data, 6-12 October 1996, Budapest. Hungarian Meteorological Service, Budapest, p 63-82

Caussinus H, Mestre O (2004) Detection and correction of artificial shifts in climate series. Appl Stat 53:405-425

Costa AC, Negreiros J, Soares A (2008) Identification of inhomogeneities in precipitation time series using stochastic simulation. In: Soares A, Pereira MJ, Dimitrakopoulos R (eds) geoENV VI: geostatistics for environmental applications. Springer, Heidelberg, p 275-282

C Craddock JM (1979) Methods of comparing annual rainfall records for climatic purposes. Weather 34:332-346

* Domonkos P (2011) Adapted Caussinus-Mestre algorithm for networks of temperature series (ACMANT). Int $\mathrm{J}$ Geosci 2:293-309

Domonkos P (2014) The ACMANT2 software package. In: Lakatos M, Szentimrey T, Marton A (eds) Eighth seminar for homogenization and quality control in climatological databases and third conference on spatial interpolation techniques in climatology and meteorology, 12-16 May 2014, Budapest. WCDMP No. 84. WMO, Geneva, p 46-72

Nomonkos P (2017) Time series homogenisation with optimal segmentation and ANOVA correction: past, present and future. In: Szentimrey T, Lakatos M, Hoffmann L (eds) Ninth seminar for homogenization and quality control in climatological databases and fourth conference on 
spatial interpolation techniques in climatology and meteorology, 3-7 April 2017, Budapest. WCDMP No. 85. WMO, Geneva, p 29-45

Domonkos P, Coll J (2017) Homogenisation of temperature and precipitation time series with ACMANT3: method description and efficiency tests. Int $\mathrm{J}$ Climatol 37 : 1910-1921

DWD (Deutscher Wetterdienst) (2011) Annual bulletin on the climate in WMO Region VI-Europe and Middle East. DWD, Offenbach am Main

Gubler S, Hunziker S, Begert M, Croci Maspoli M and others (2017) The influence of station density on climate data homogenization. Int J Climatol 37:4670-4683

Guijarro J (2006) Homogenization of a dense thermo-pluviometric monthly database in the Balearic Islands using the free contributed $\mathrm{R}$ package 'climatol'. In: Lakatos $\mathrm{M}$, Szentimrey T, Bihari Z, Szalai S (eds) Proc $5^{\text {th }}$ seminar for homogenization and quality control in climatological databases, 29 May-2 June 2006, Budapest. WCDMP No. 71. WMO, Geneva, p 25-36

Guijarro JA (2011) User's guide to climatol. An R contributed package for homogenization of climatological series. www.climatol.eu/climatol-guide.pdf

Guijarro JA (2018) Homogenization of climatic series with Climatol. www.climatol.eu/homog_climatol-en.pdf

Hartmann DL, Klein Tank AMG, Rusticucci M, Alexander LV and others (2013) Observations: atmosphere and surface. In: Stocker TF, Qin D, Plattner GK, Tignor M and others (eds) Climate change 2013: the physical science basis. Contribution of Working Group I to the Fifth Assessment Report of the Intergovernmental Panel on Climate Change. Cambridge University Press, Cambridge, p 159-254

ISPRA (2017) Stato dell'Ambiente-Gli indicatori del clima in Italia nel 2015, ISPRA, Stato dell'Ambiente 72/2017 (in Italian)

Lindau R, Venema V (2016) The uncertainty of break positions detected by homogenization algorithms in climate records. Int J Climatol 36:576-589

Liuzzo L, Bono E, Sammartano V, Freni G (2017) Long-term temperature changes in Sicily, southern Italy. Atmos Res 198:44-55

Mamara A, Argiriou AA, Anadranistakis M (2014) Detection and correction of inhomogeneities in Greek climate temperature series. Int J Climatol 34:3024-3043

Marletto V, Antolini G, Tomei F, Pavan V, Tomozeiu R (2009) Atlante idroclimatico dell'Emilia-Romagna 1961-2008. ARPA Emilia-Romagna, Bologna. www.arpa.emr.it/sim/? clima (accessed 8 May 2015)

Editorial responsibility: Eduardo Zorita, Geesthacht, Germany
Menne MJ, Williams CN Jr (2009) Homogenization of temperature series via pairwise comparisons. J Clim 22: 1700-1717

Mestre O, Domonkos P, Picard F, Auer I and others (2013) HOMER: a homogenization software-methods and applications. Q J Hung Meteorol Ser 117:47-67

\% Osadchyi V, Skrynyk O, Radchenko R, Skrynyk O (2018) Homogenization of Ukrainian air temperature data. Int J Climatol 38:497-505

* Pettitt AN (1979) A non-parametric approach to the changepoint problem. Appl Stat 28:126-135

* Picard F, Lebarbier E, Hoebeke M, Rigaill G, Thiam B, Robin S (2011) Joint segmentation, calling, and normalization of multiple CGH profiles. Biostatistics 12:413-428

* Ribeiro S, Caineta J, Costa AC (2016) Review and discussion of homogenisation methods for climate data. Phys Chem Earth 94:167-179

Ribeiro S, Caineta J, Costa AC, Henriques R (2017) gsimcli: a geostatistical procedure for the homogenisation of climatic time series. Int J Climatol 37:3452-3467

Scorzini AR, Di Bacco M, Leopardi M (2018) Recent trends in daily temperature extremes over the central Adriatic region of Italy in a Mediterranean climatic context. Int J Climatol 38(Suppl 1):e741-e757

Szentimrey T (1999) Multiple Analysis of Series for Homogenization (MASH). In: Proc $2^{\text {nd }}$ seminar for homogenization of surface climatological data, 9-13 November 1998, Budapest. WCDMP No. 41. WMO, Geneva, p 27-46

Toreti A, Desiato F (2008) Temperature trend over Italy from 1961 to 2004. Theor Appl Climatol 91:51-58

Trenberth KE, Jones PD, Ambenje P, Bojariu R and others (2007) Observations: surface and atmospheric climate change. In: Solomon S, Qin D, Manning M, Chen Z and others (eds) Climate change 2007: the physical science basis. Contribution of Working Group I to the Fourth Assessment Report of the Intergovernmental Panel on Climate Change. Cambridge University Press, Cambridge, p 235-336

* Venema VKC, Mestre O, Aguilar E, Auer I and others (2012) Benchmarking homogenization algorithms for monthly data. Clim Past 8:89-115

Wang XL (2008) Accounting for autocorrelation in detecting mean shifts in climate data series using the penalized maximal $t$ or F test. J Appl Meteorol Climatol 47:2423-2444

WMO (2011) Guide to climatological practices, Vol 100. World Meteorological Organization, Geneva

WMO (2016) WMO Climatological Standard Normals, Chapter 4, Item 4.8 (updated 19.01.2016). World Meteorological Organization, Geneva

Submitted: July 24, 2018; Accepted: December 20, 2018

Proofs received from author(s): February 22, 2019 